\title{
Two new species of the genus Allochthonius Chamberlin from China (Pseudoscorpiones: Pseudotyrannochthoniidae)
}

\author{
Junfang Hu \& Feng Zhang*
}

Hu, J. \& Zhang, F. 2011: Two new species of the genus Allochthonius Chamberlin from China (Pseudoscorpiones: Pseudotyrannochthoniidae). - Entomol. Fennica 22: 243-248.

Two new pseudoscorpion species of Allochthonius are described: Allochthonius (Allochthonius) liaoningensis sp. n. and A. (Urochthonius) brevitus sp. n. The latter represents species of the subgenus Allochthonius (Urochthonius) found in China for the first time.

J. F. Hu, College of Life Sciences, Hebei University, Baoding, Hebei 071002, China; E-mail: jfanghu@gmail.com

F. Zhang (*corresponding author), College of Life Sciences, Hebei University, Baoding, Hebei 071002, China; E-mail:dudu06042001@163.com

Received 30 November 2011, accepted 4 January 2012

\section{Introduction}

The family Pseudotyrannochthoniidae Beier is composed of five genera, Afrochthonius Beier, Allochthonius Chamberlin, Centrochthonius Beier, Pseudotyrannochthonius Beier and Selachochthonius Chamberlin (Harvey 2011). Only two of them, Allochthonius and Centrochthonius, have been reported from China. Allochthonius is currently divided into two subgenera, Allochthonius (Allochthonius) and Allochthonius (Urochthonius), of which the former is composed of 12 species and two subspecies (Harvey 2011, $\mathrm{Hu} \&$ Zhang 2011), and the latter includes two species and six subspecies (Harvey 2011).

While examining pseudoscorpion specimens collected from Ningxia Hui Autonomous Region, Jilin and Liaoning provinces, China, we found two Allochthonius species belonging to the subgenera Allochthonius (Allochthonius) and Allochthonius (Urochthonius), respectively. They are illustrated and described under the names $A$. (A.) liaoningensis sp. n. and $A$. (U.) brevitus sp. n. in this paper. Allochthonius $(U$.) brevitus also represents the first record of the subgenus Allochthonius (Urochthonius) from China.

\section{Material and methods}

The terminology used in this paper follows Chamberlin (1931), Harvey (1992) and Judson (2007). The setal formulae of the palpal femur mainly follows Vachon (1941), but differs in that we divided the "ventral" into "posteroventral" and "anteroventral" (rows in sequence anterioranterodorsal-dorsal-posterodorsal-posteriorposteroventral-anteroventral). The term "rallum" (for flagellum) is adopted following Judson (2007).

All specimens are preserved in 75\% alcohol, and were examined and illustrated using a Leica M165c stereomicroscope with a drawing tube, which was also used for the measurements. Detailed examination was carried out with a Nikon YS100 general optical microscope. Temporary slide mounts were made in glycerol. All measurements are given in $\mathrm{mm}$. The specimens are depos- 


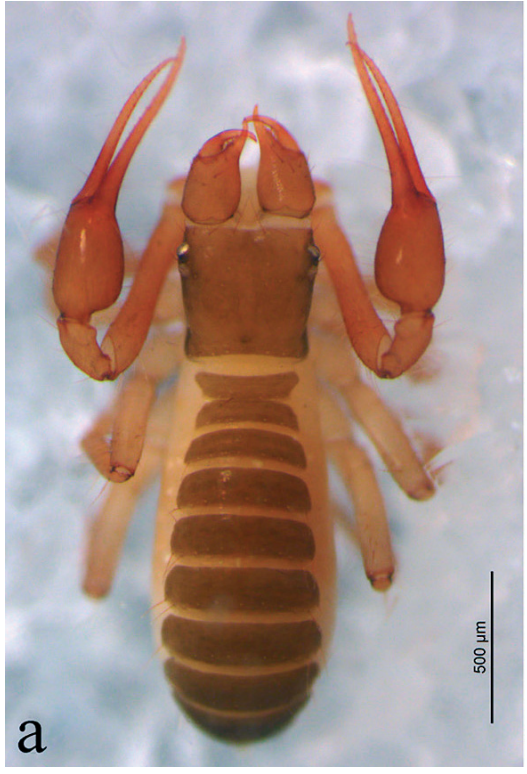

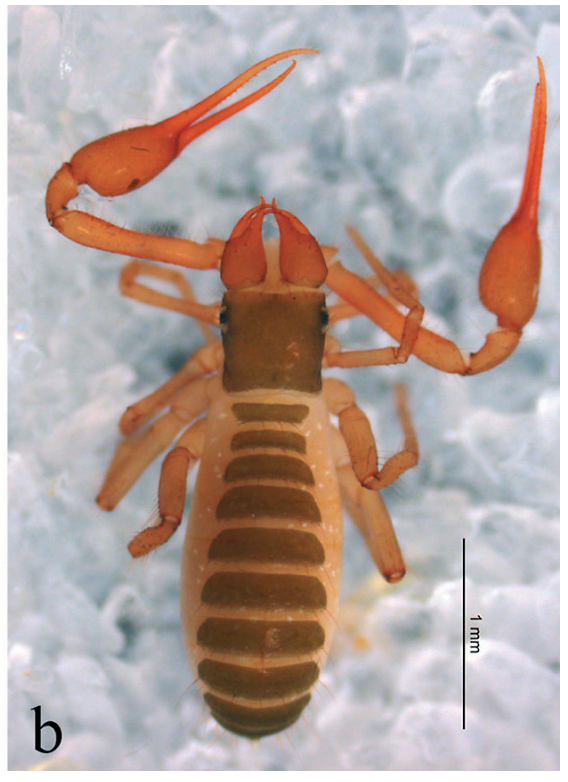

Fig 1. Allochthonius (Allochthonius) liaoningensis sp. $\mathbf{n}$. - a. Male habitus (dorsal view). - b. Female habitus (dorsal view). ited in the Museum of Hebei University (MHBU), Baoding City, China.

The following abbreviations are used in the text for the trichobothria: $b=$ basal; $s b=$ subbasal; $s t=$ sub-terminal; $t=$ terminal; $i b=$ interior basal; is $b=$ interior sub-basal; ist = interior subterminal; $i t=$ interior terminal; $e b=$ exterior basal; es $b=$ exterior sub-basal; est = exterior subterminal; et $=$ exterior terminal; $d x=$ duplex trichobothria. 6-4, 18 refers to carapacal chaetotaxy: carapace with 18 setae, anterior margin with 6 setae and posterior margin with 4 setae.

\section{Taxonomy}

\subsection{Subgenus Allochthonius (Allochthonius)}

Allochthonius (Allochthonius) Chamberlin: Morikawa, 1960: 98; Harvey, 1991: 132; Hu \& Zhang, 2011: 2168-2169.

Allochthonius (Allochthonius) liaoningensis sp. n. (Figs. 1-2)

Type material. Holotype male (Museum ID \# Ps.MHBU-LN110822): China, Liaoning Province, Xingbin County, 41 ${ }^{\circ} 57^{\prime} \mathrm{N} 124^{\circ} 26^{\prime} \mathrm{E}, 22$.VIII. 2011, Chao Zhang leg. Paratypes: one male (Museum ID \# Ps.-MHBU-LN11082201), two fe- males (Museum ID \# Ps.-MHBU-LN1108220211082203), same data as for holotype. One male (Museum ID \# Ps.-MHBU-LN11082301) and three females (Museum ID \# Ps.-MHBULN11082302-11082304), Liaoning Province, Qingyuan County, $42^{\circ} 03^{\prime} \mathrm{N} 124^{\circ} 27^{\prime} \mathrm{E}, 23$.VIII. 2011, Chao Zhang leg. One male (Museum ID \# Ps.-MHBU-LN11081401) and one female (Museum ID \# Ps.-MHBU-LN11081402), Jilin Province, Baishan City, Jiangyuan County, $42^{\circ} 02^{\prime} \mathrm{N}$ $127^{\circ} 06^{\prime} \mathrm{E}, 14$.VIII.2011, Chao Zhang leg. Three females (Museum ID \# Ps.-MHBU-LN1108 2302-11082304), Jilin Province, Huadian City, Jiapigou Town, 4251'N 127³1'E, 8.VIII.2011, Chao Zhang leg.

Diagnosis. This species is characterized by the retrorse teeth on the chelal movable finger, and the shape of the coxal spines present on coxae I, each blade having a central spine terminally that is distinctly expanded into a fan-shaped structure, all situated on a common tubercle (Fig. $2 \mathrm{~h})$.

Description. Body deep yellowish brown, chelicerae and palps reddish brown (Fig. 1).

Carapace (Fig. 2a) subquadrate and slightly shorter than broad (0.91-0.94 times in males and 0.84-0.87 times in females), carapace slightly constricted posteriorly; anterior eyes with well developed tapeta and situated on tubercles, posterior eyes with less developed tapeta than anterior 
Fig 2. Allochthonius (Allochthonius) liaoningensis sp. $\mathbf{n}$. - a. Male carapace (dorsal view). - b. Male right chelicerae (dorsal view). - c. Male left
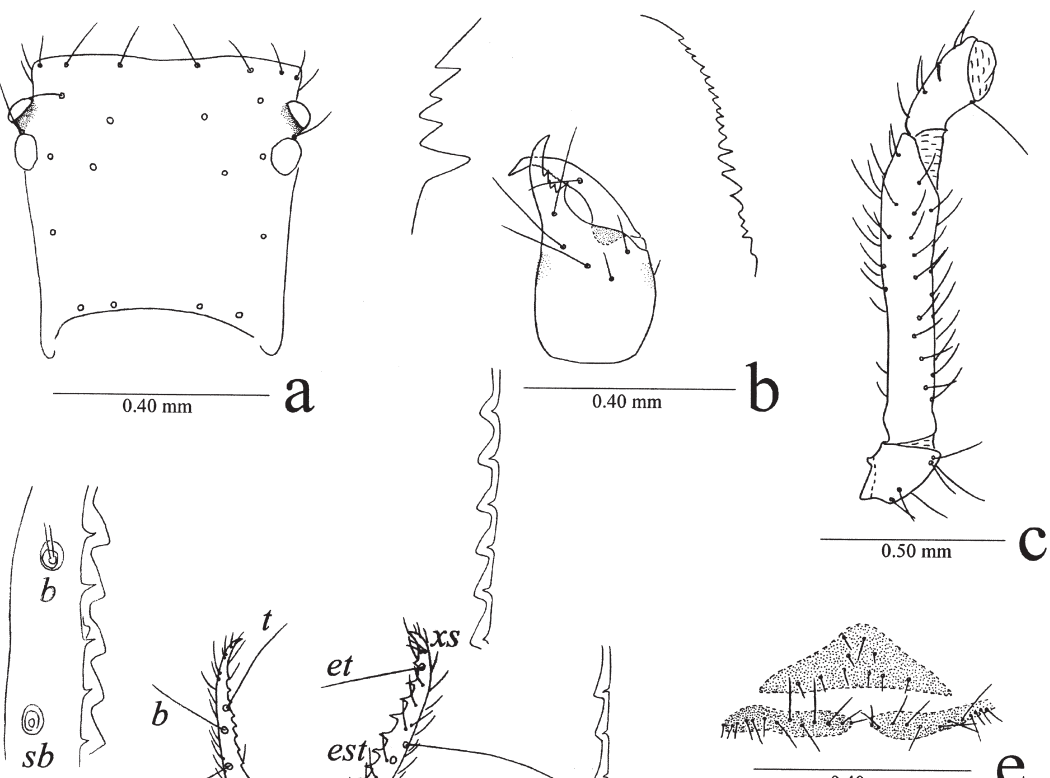

palp (minus chela, dorsal view). - d. Male left chela (lateral view). - e. Female genital (ventral view). $-f$. Male genital (ventral view). - g. Male leg I (lateral view).

$-h$. Male coxal spines on leg I (ventral view). -i. Male leg IV (lateral view).
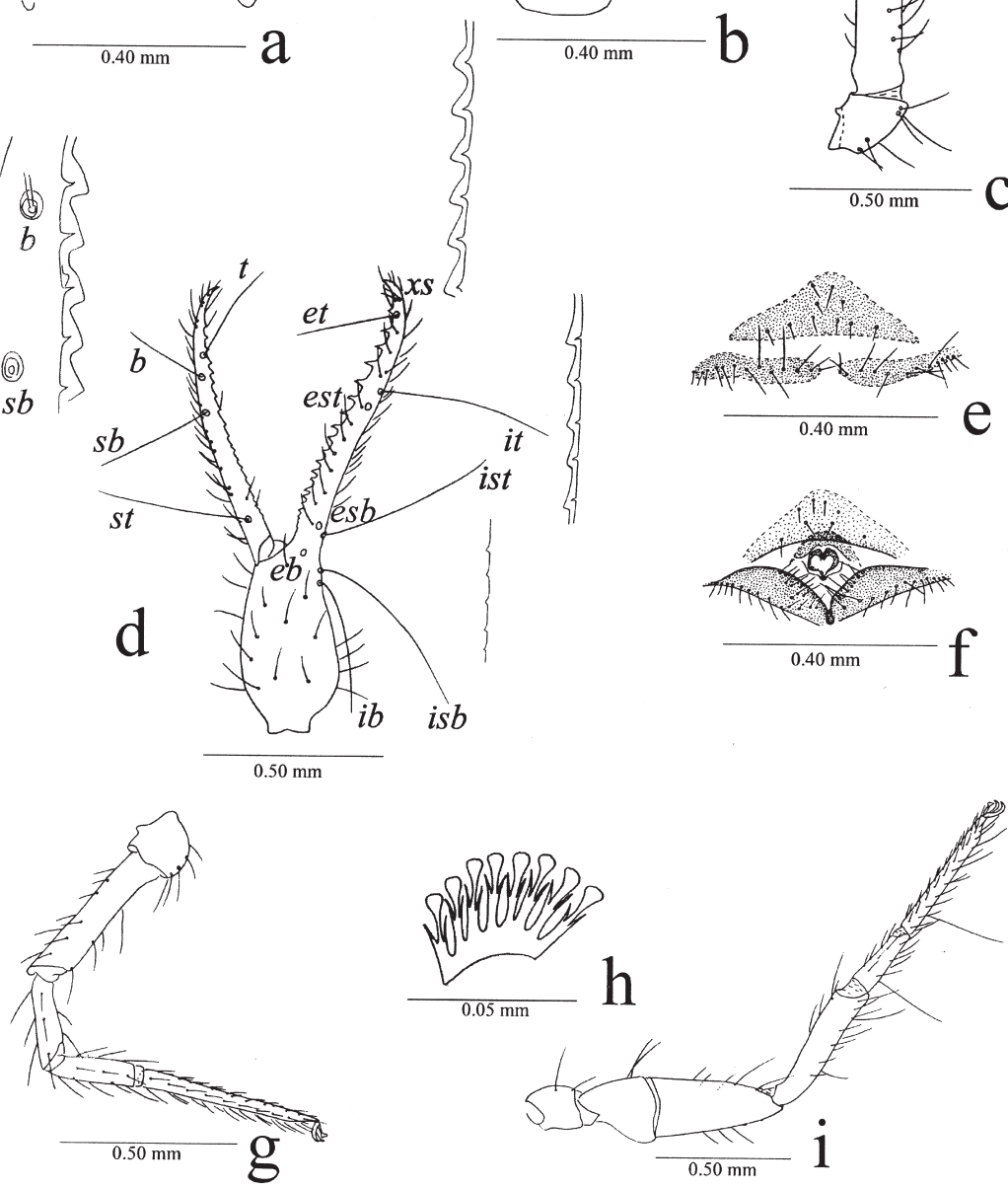

eyes and not situated on tubercles; epistome absent, space between median setae straight or slightly recurved; chaetotaxy 10-4-4-2-4 (24).

Male tergal chaetotaxy, $4: 6: 7-8: 8: 10-11$ : 11: 12-13: 11-12: 10-11: 7-9: TT: 0; anterior genital operculum (Fig. 2f) with 8 setae, genital opening pit-like in the basal half, 9-10 marginal setae on each side; sternal chaetotaxy: 21-26: 1820: 17: 16-17: 15-18: 14-15: 14: 12: 0: 2; coxae typical, setae P 5, I 5, II 6, III 6-7, IV 7; intercoxal tubercle present with two setae. Female tergal chaetotaxy, 4: 6: 8-10: 8-9: 10-11: 10-11: 1011: 11-12: 9-11: 6-7: TT: 0; anterior genital operculum (Fig. 2e) with 10 setae, posterior margin with 25 marginal setae; sternal chaetotaxy: 20: 16-17: 16-17: 15-16: 14-15: 12-14: 9: 0: 2; setae P 5, I 4-5, II 5-7, III 6, IV 7. Coxae I each with 8 spines, arranged on a common tubercle (Fig. 2h).

Cheliceral (Fig. 2b) palm with 6 setae, of which a minute one is located laterally; palm with moderate hispid granulation interiorly and later- 
ally. Fixed finger with 4 teeth, of which the basal and subapical teeth large and with two small teeth between them; movable finger with 18 relatively small acute teeth of equal length; spinneret absent. Serrula exterior with 17-18 lamellae, serrula interior with 15 lamellae. Rallum composed of 12 blades with fine barbules, of which the posterior blade is shorter than others.

Palp (Figs. 2c-d) smooth, femur 1.64-1.73 times longer than carapace, setal formula 9-4-65-9-1-1; chelal finger straight in dorsal view; fixed finger with 20 teeth, the basal 4 teeth smaller than the others; movable finger with 20 retrorse teeth, all of which nearly equal length and smaller, with a small tubercle near the teeth between trichobothria $s b$ and $b$.

Legs (Figs. 2g, 2i) typical. Femur of leg I 1.55-1.67 times longer than patella, tarsus 2.002.20 times longer than tibia, setae of leg I (trochanter to tibia) 5: 13:12:14, setae of leg IV (trochanter to metatarsus) $3: 2: 10: 15: 12$; patellae of legs III and IV each with 5 setae in dorsal row; femur III and IV without dorsal setae; trochanter II with 5 setae, trochanter III with 3 setae. Leg IV with 2 tactile setae present on metatarsus $(\mathrm{TS}=0.21)$ and tarsus $(\mathrm{TS}=0.19)$.

Measurements (in $\mathrm{mm}$, ratios in parentheses). Male. Body length 2.00-2.13. Carapace 0.50$0.51 \times 0.53-0.56 \quad(0.91-0.94)$. Chelicera 0.50 $0.53 \times 0.23-0.24(2.17-2.21)$, movable finger length $0.25-0.29$. Palpal trochanter $0.25 \times 0.15$ 0.17 (1.47-1.67), femur $0.82-0.88 \times 0.16-0.17$ (5.13-5.18), patella $0.30-0.35 \times 0.15-0.16(2.00$ 2.19), chela $1.28-1.30 \times 0.27-0.28$ (4.64-4.74), palm length $0.45-0.48(1.67-1.71)$, movable finger length $0.77-0.80(1.67-1.71 \times$ palm $)$. Leg I femur $0.45-0.50 \times 0.10-0.11(4.50-4.55)$, patella $0.29-0.30 \times 0.09-0.10(3.00-3.22)$, tibia $0.25 \times$ 0.06-0.07 (3.57-4.17), tarsus $0.50-0.55 \times 0.05-$ $0.06(9.17-10.00)$; leg IV femur+patella 0.70 $0.73 \times 0.25-0.26(2.80-2.81)$, tibia $0.55 \times 0.10$ $0.11(5.00-5.55)$, metatarsus $0.25-0.28 \times 0.08$ (3.13-3.50), tarsus $0.52-0.55 \times 0.05-0.06(9.17-$ 10.4).

Female. Body length 1.95-2.13. Carapace $0.52-0.53 \times 0.60-0.63 \quad(0.84-0.87)$. Chelicera $0.55 \times 0.28$ (1.96), movable finger length 0.30 . Palpal trochanter $0.25-0.26 \times 0.16-0.17$ (1.531.56), femur $0.95-0.98 \times 0.17-0.18$ (5.44-5.59), patella $0.33-0.38 \times 0.17-0.18(1.94-2.11)$, chela

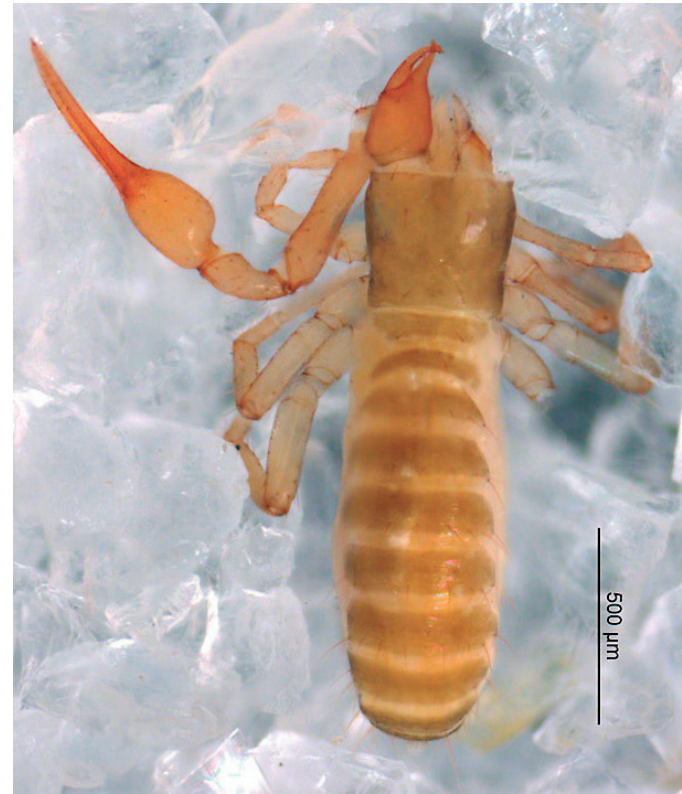

Fig 3. Allochthonius (Urochthonius) brevita sp. $\mathbf{n}$. - Female habitus (dorsal view).

$1.45 \times 0.33-0.34(4.26-4.39)$, palm length 0.46 0.50 (1.39-1.47), movable finger length 0.85 0.88 (1.76-1.85×palm). Leg I femur 0.45-0.50× $0.11-0.12$ (4.09-4.17), patella $0.30-0.32 \times 0.09$ $0.10(3.20-3.33)$, tibia $0.26-0.27 \times 0.07-0.08$ (3.38-3.71), tarsus $0.50-0.55 \times 0.05-0.06(9.17-$ 10.00); leg IV femur+patella $0.75-0.80 \times 0.27$ 0.28 (2.78-2.86), tibia $0.55-0.60 \times 0.11-0.12$ (5.00), metatarsus $0.28-0.30 \times 0.08-0.09$ (3.33$3.50)$, tarsus $0.55-0.58 \times 0.06-0.07$ (8.29-9.17).

Etymology. This species is named for the type locality.

Distribution. China (Jilin, Liaoning).

Remarks. This species differs from the other members of the subgenus Allochthonius (Allochthonius) in having retrorse teeth on the chelal movable finger.

\subsection{Subgenus Allochthonius (Urochthonius)}

Allochthonius (Urochthonius) Morikawa, 1954: 80; Morikawa, 1960: 101; Harvey, 1991: 133.

Allochthonius (Urochthonius) brevitus sp. n. (Figs. 3-4) 
Fig 4. Allochthonius (Urochthonius) brevita sp. n. Holotype female. - a. Carapace (dorsal view). - b. Right chela (lateral view). - c. Right palp (minus chela, dorsal view). - d. Right chelicera (dorsal view). - e. Genital area (ventral view). $-f$. Coxal areas of legs (ventral view). - g. Leg IV.
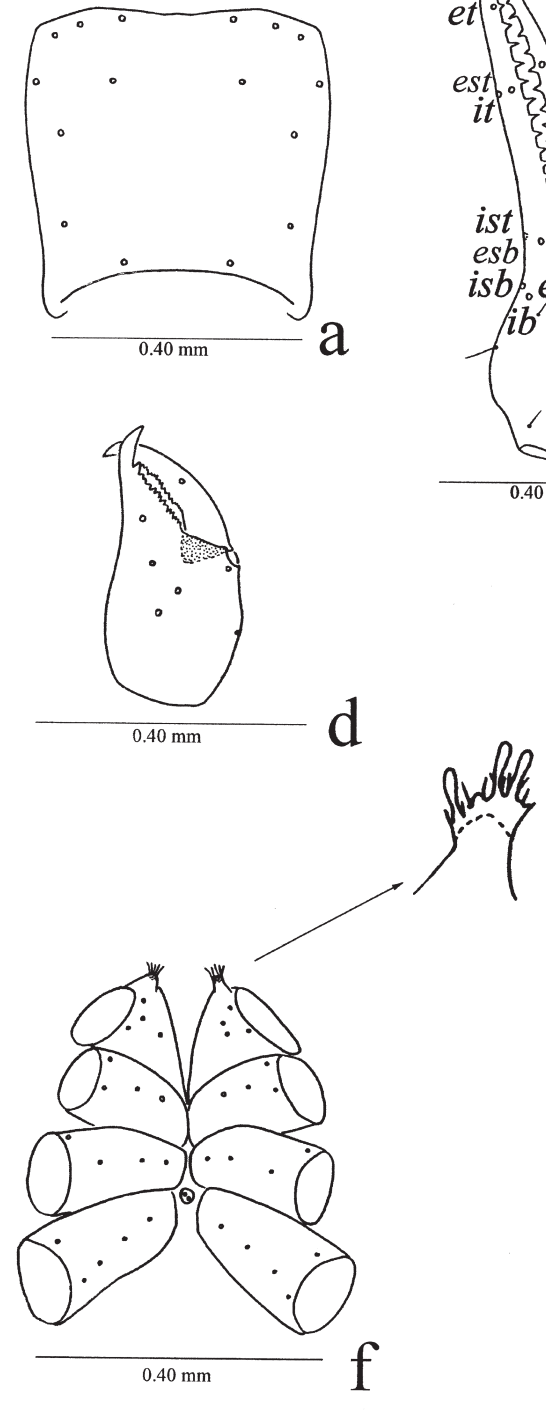
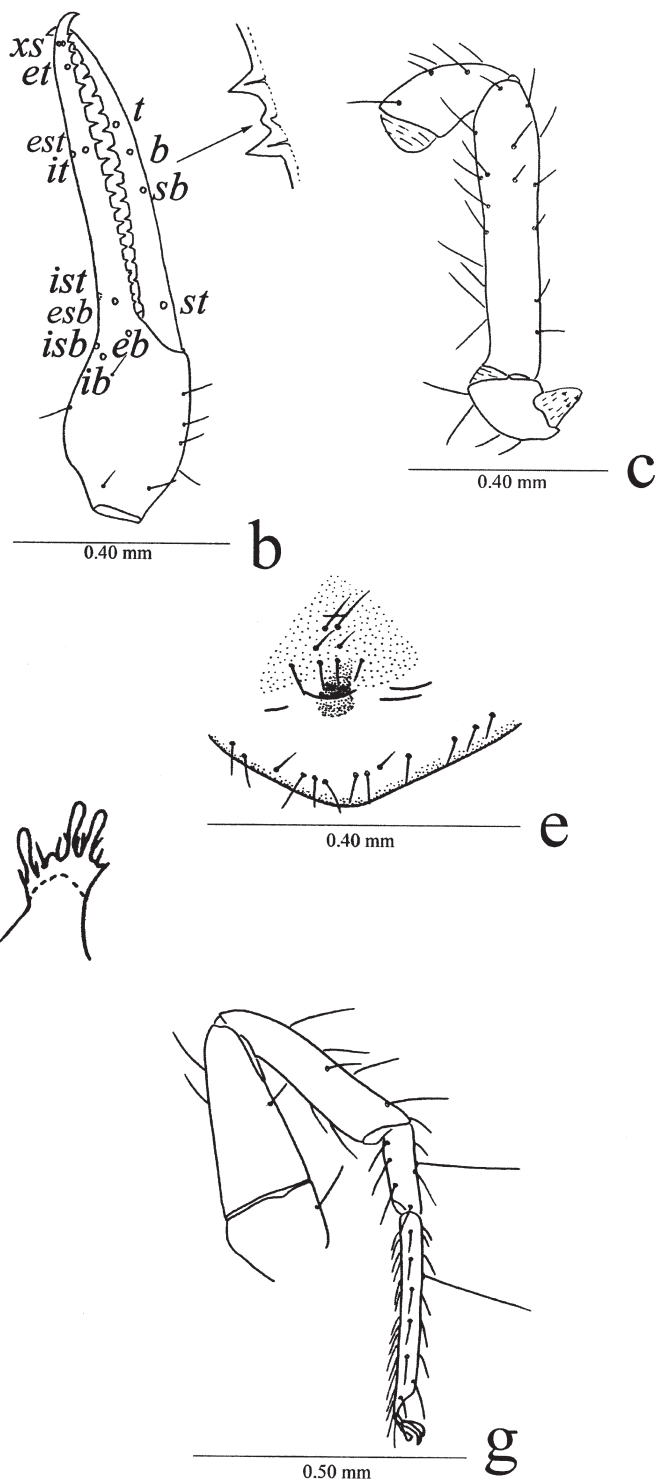

Type material. Holotype female (Museum ID \# Ps.-MHBU-NX100731): China, Ningxia Hui Autonomous Region, Liupan Mountain, 3520'N 106²0’E, 31.VII.2010, Dongsheng Hu leg.

Diagnosis. The new species differs from the other species of Allochthonius (Urochthonius) in the stout palp and coxal spines present on coxae I consisting of 6 tridentate blades, the central one of each blade terminally distinctly spatulate (Fig. 4f).

Description. Body light yellowish, chelicerae and palp reddish, carapace and tergites strong yellowish brown (Fig. 3). Carapace (Fig. 4a) slightly shorter than broad (0.95 times) and constricted posteriorly, chaetotaxy 6-4-2-2-2 (26); without eyes or eyespots; chaetotaxy of tergites: $2: 6: 7: 8$ : 9: 8 ( 2 submedian tactile setae): 8 ( 2 submedian tactile setae): 7 (2 submedian tactile setae): 6 (2 submedian tactile setae): 5: 2: 0; setae P 3, I 4, II 4, III 4, IV 5; coxae I each with 5 spines, all of which arranged on a common tubercle (Fig. 4f), intercoxal tubercle present with 2 setae; genital operculum (Fig. 4e) with 8 setae, chaetotaxy of sternites: 13: 15: 15: 14: 15: 12: 8 (2 submedian tactile setae +2 lateral tactile setae): 4 (2 submedian tactile setae +2 lateral tactile setae): 2 . 
Cheliceral palm (Fig. 4d) with 6 setae, fixed finger with 14 teeth, of which the distal tooth is larger than the others, movable finger with 20 teeth of equal length; spinneret absent, serrula exterior 19 lamellae, serrula interior 14 lamellae, rallum composed of 11 anteriorly dentate blades, 5 in one row and 6 in another row.

Palpal femur (Fig. 4c) chaetotaxy: 7-2-3-5$1-1-0$; fixed chelal finger with 20 pointed teeth of equal length, the basal two shorter than the others; movable finger with 17 marginal teeth and the basal two shorter, between the eighth and ninth with a tubercle (Fig. 4b); trichobothrium sb indistinctly nearer $b$ than $s t$, it and est at level of $t$, line $i b$-is $b-e b-e s b$-ist clustered at the base of fixed finger.

Leg I femur 1.50 times longer than patella, tarsus 1.80 times longer than tibia. Leg IV (Fig. $4 \mathrm{~g}$ ) with two tactile setae present on metatarsus $(\mathrm{TS}=0.30)$ and tarsus $(\mathrm{TS}=0.32)$.

Measurements (in $\mathrm{mm}$, ratios in parentheses). Body length 1.88. Carapace 0.48/0.50 (0.96). Chelicera 0.43/0.23 (1.87), movable finger 0.20. Palpal trochanter $0.18 / 0.13$ (1.38), femur $0.58 /$ 0.15 (3.87), patella $0.25 / 0.13$ (1.92), chela $0.98 /$ 0.23 (4.26), palm length $0.30 / 0.23$ (1.30), movable finger length 0.65 . Leg I femur $0.30 / 0.08$ (3.75), patella $0.20 / 0.08$ (2.50), tibia $0.20 / 0.08$ (2.50), tarsus $0.35 / 0.05$ (7.00); leg IV femur+patella $0.60 / 0.30(2.00)$, tibia $0.38 / 0.10(3.80)$, metatarsus $0.18 / 0.08(2.25)$, tarsus $0.35 / 0.08$ (4.38).

Etymology. The specific name is derived from the Latin word "brevitas" means shortness, referring to the shape of palpal femur.

Distribution. China (Ningxia Hui Autonomous Region).

Remarks. The subgenus Allochthonius (Urochthonius) is composed of two species and six subspecies, all from Japan. The new species Allochthonius (Urochthonius) brevitus sp. n., collected from Ningxia Hui Autonomous Region, represents the first record of Allochthonius (Urochthonius) from mainland Asia. It differs from the other Allochthonius (Urochthonius) species in having a stouter palpal femora (3.87 times as long as broad, compared with more than 5 times in A. (U.) ishikawai Morikawa, 1954 and $A$. (U.) biocularis Morikawa, 1956). In addition, $A$. $(U$.) biocularis has one pair of elevated and vestigial eyes, whereas eyes are absent from $A$. (U.) ishikawai and A. (U.) brevitus. Allochthonius (U.) ishikawai has 5 setae on the cheliceral palm, while $A$. (U.) brevitus has 6 setae.

Acknowledgements. This work greatly benefited from Dr Hidebumi Sato (Tsurumi Girls' Senior High School) for kindly donating valuable literature. We are also grateful to the referees for their valuable comments on the text. Many thanks are also given to Dr Dongsheng Hu and Chao Zhang who collected the specimens. This work was supported by the National Natural Science Foundation of China (Nos. 31071885, 30970325, 31093430).

\section{References}

Chamberlin, J. C. 1931: The arachnid order Chelonethida. - Stanford University Publications, University Series (Biol. Sci.) 7: 1-284.

Harvey, M. S. 1991: Catalogue of the Pseudoscorpionida. - Manchester University Press, Manchester. Pp. 1726.

Harvey, M. S. 1992: The phylogeny and classification of the Pseudoscorpionida (Chelicerata: Arachnida). Invertebrate Taxonomy 6: 1373-1435.

Harvey, M. S. 2011: Pseudoscorpions of the World, version 2.0. - Western Australian Museum, [www document]. URL http://www.museum.wa.gov.au/catalogues/pseudoscorpions. (Site visited on 27 November, 2011)

Hu, J. F. \& Zhang, F. 2011: Description of three new species of the genus Allochthonius Chamberlin, 1929 (Pseudoscorpiones: Pseudotyrannochthoniidae) from China. - Journal of Threatened Taxa 3: 2167-2176.

Judson, M. L. I. 2007: A new and endangered species of the pseudoscorpion genus Lagynochthonius from a cave in Vietnam, with notes on chelal morphology and the composition of the Tyrannochthoniini (Arachnida, Chelonethi, Chthoniidae). - Zootaxa 1627: 53-68.

Morikawa, K. 1954: On some pseudoscorpions in Japanese lime-grottoes. - Memoirs of Ehime University (2B) 2: 79-87.

Morikawa, K. 1956: Cave pseudoscorpions of Japan (I).Memoirs of Ehime University (2B) 2: 271-282.

Morikawa, K. 1960: Systematic studies of Japanese pseudoscorpions. - Memoirs of Ehime University (2B) 4: 85-172.

Vachon, M. 1941: Chthonius tetrachelatus P. (Pseudoscorpions) et ses formes immatures (1re note). - Bulletin du Muséum national d'Histoire naturelle, Paris (2) 13 : 442-449. 